\title{
The determination of sorption material properties for water softening in the dynamic conditions
}

\author{
${ }^{*}$ Vladimir Somin ${ }^{1}$, Lubov Kurtukova ${ }^{1}$ and Larisa Komarova ${ }^{1}$ \\ ${ }^{1}$ Altay Technical University, Barnaul, Russia
}

\begin{abstract}
Hardness ions sorption properties of bentonite and paraffine-based material have been studied under dynamic conditions. The temporal characteristics of sorption process have been defined. The comparative analysis of obtained sorbent with cation exchange resin «Lewatit» has been implemented.
\end{abstract}

\section{Introduction}

Natural water softening is the urgent problem for many areas of Altai region, where there are almost no surface water sources and available ground water sources are characterized by heightened content of some elements, including the hardness salts. The content of hardness salts can fluctuate from $0,01 \mathrm{mg}-\mathrm{Eq} / \mathrm{L}$ to $7 \mathrm{mg}-\mathrm{Eq} / \mathrm{L}$ depending on the category and function of water $[2,3]$.

The traditional softening water methods are chemical and thermochemical methods, reverse osmosis and ion exchange. These methods are high-efficiency, but they demand significant costs of energy and resources. Recently the technologies based on using of sorption and ion exchanging materials from natural mineral raw material are introduced with the purpose of cost minimization on cleaning $[4,5]$.

The most known group of mineral sorbents is the bentonite clay, that forms big deposits in nature and has an industrial value. At present there is a considerable amount of known bentonite deposits in the USA, France, India, Greece, Russia, Kazakhstan, Georgia, Armenia and other countries.

For effective usage of bentonite clay exchange capacity it is necessary to expose clay to preliminary activation for calcium and magnesium ions replacement by more mobile ions (sodium and hydrogen) in the crystal lattice structure [6]. And it is necessary to consider the nature of extractive substance and bentonite content. For metal ions removing from water solutions there are the following types of bentonite clay activations: heat, acid, salt and soda. The conducted research showed a higher efficiency of soda activation with the following extraction of hardness compounds for bentonites of all considered fields compared with other activations [7,8]. We have detected, that the Millos bentonite (Greece) of soda activation has the highest static hardness ions sorption capacity $(1,9 \mathrm{mg}-\mathrm{Eq} / \mathrm{L})$.

The sorption properties of this clay are comparable with sorption properties of ion exchange resin in the static conditions, named «Lewatit», using for softening.

\footnotetext{
*Corresponding author: vladimir_somin@mail.ru
} 
In dynamic conditions it is impossible to use bentonite because of high hydraulic resistance and the infiltration carryover with flow. In connection with this research of bentonite clay fixation on different frames including the mineral fiber and waste wood are carried out in the Altai State Technical University at the department of Chemical technique and Engineering ecology [10,11]. The alternative version is paraffin, that can be used as a bonding agent. The obtained material has showed the high denotation of sorption capacity on hardness ions in static condition [9]. Determination sorption parameters in dynamic condition is more important for organization of technological process and so further research has been directed to of full dynamic exchange capacitance of this material studying.

\section{Experimental}

The research of filtration process through bentonite packing is complicated by high hydraulic resistance due to the ability to swell in the water and fill the loading channels. That is why it has been decided to use the "soft» filtration method, that has been conducted without water slick formation above the filtration material and the water is evenly distributed as a film on its surface.

The full dynamic capacity determination was realized by method GOST 20255.2-89 [12] by the way of water solution filtration of hardness salts through the module with an inside diameter of 35 millimeters, with packing material weight of 40 grams and height of 21 centimeters. Sorbent packing was made layer by layer with distributive grids using, that laid between material layers. The solution quantity flow was $26 \mathrm{ml} /$ minute, the filtration speed was 1,6 meters/hour. The discharge under the material layer was made by vacuum-filter.

The model solution was applied with the content of hardness ions $10 \mathrm{mg}-\mathrm{Eq} / \mathrm{L}$, which was used for the preparation of calcium chloride analytical reagent grade and magnesium sulfate heptahydrate. Ions ratio of calcium and magnesium was $2: 1$, it is more appropriate for natural waters of Altai region. Sample picking of $15-20 \mathrm{ml}$ volume was been realized after every $100 \mathrm{ml}$ of filtrate, after that the sample was analyzed for the content of total hardness by titrometric method with chelating agent III with $\mathrm{pH}=10$ using and indicator Black Eriochrome [13] presence. The process was carried out to equalize the filtrate and working solution.

The full dynamic exchanging capacity $\left(D_{\Pi}\right)$ was calculated in moles per gram $(\mathrm{mg}-\mathrm{Eq} / \mathrm{g})$ by the formula (1):

$$
\mathrm{D}_{\mathrm{\Pi}}=\left(\left(\mathrm{V}_{\phi} \cdot \mathrm{C}-\Sigma \mathrm{V}_{\Pi} \cdot \mathrm{C}_{\mathrm{\Pi}}\right) \cdot 1000\right) / \mathrm{m}
$$

where: $\mathrm{V}_{\phi}$ - the total filtrate volume, passing through the material to equalize the filtrate and working solution, cc;

$\mathrm{C}$-concentration of working solution, mole/cdm;

$\mathrm{V}_{\Pi}$-filtrate portion volume, cc;

$\mathrm{C}_{\mathrm{n}}$-solution concentration in the filtrate portion, mole/cdm ;

$\mathrm{m}$-sorbent weight, $\mathrm{g}$.

The value of full exchange capacity of sorbent was being determined before and after regeneration. The regeneration of researched sorption and ion-exchange material was being implemented by $5 \%$ sodium hydrogen carbonate solution, after that there was the washing sorbent off by distilled water.

After the first cycle of saturation (the original material) the value $\mathrm{D}_{\text {пा }}$ was $0,31 \mathrm{mg}-\mathrm{Eq} / \mathrm{g}$, after the second one (the $1 \mathrm{st}$ regeneration) it was $0,26 \mathrm{mg}-\mathrm{Eq} / \mathrm{g}$, after the third one (the $2^{\text {nd }}$ regeneration) it was $0,21 \mathrm{mg}-\mathrm{Eq} / \mathrm{g}$. As it can be seen regeneration reduces the full exchange capacity. The full dynamic exchange capacity of cation resin Lewatit was determined in comparison with the analogical condition, that came up to $0,47 \mathrm{mg}-\mathrm{Eq} / \mathrm{g}$ after the first cycle of saturation, that is comparable with bentonite-paraffin materials. 
In the research process of dynamic capacity the dependencies of ions hardness extraction effectiveness on the bentonite-paraffin materials and cation resin Lewatit from the solution with concentration of $10 \mathrm{mg}-\mathrm{Eq} / \mathrm{L}$ on the time were determined, that is shown in figure 1.

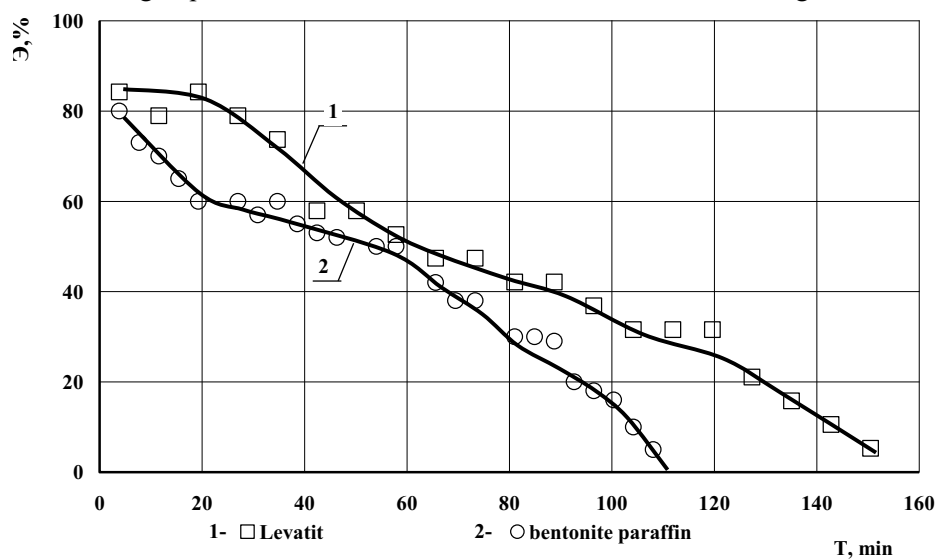

Fig. 1. The dependence of ions hardness extraction effectiveness $(\ni)$ on time $(T)$ on the bentonite paraffin materials and cation resin Lewatit.

For both materials gradual decline of effectiveness with time can be marked. The maximum of softening was $84 \%$ for Lewatit within 20 minutes with the following decrease by 5\% within 160 minutes. For paraffin-bentonite material the maximum cleaning effect came up to $80 \%$ for the first portion of filtrate with the following decrease. The full saturation was achieved within 110 minutes.

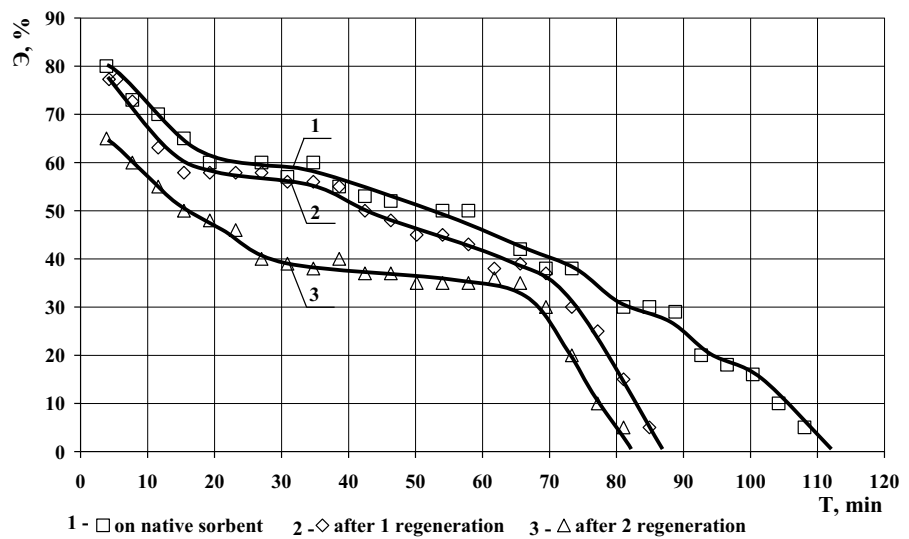

Fig. 2. The dependence of ions hardness extraction effectiveness $(\ni)$ and time $(T)$ on the bentonite paraffin materials before and after regeneration.

On figure 2 the curves of effectiveness of ions hardness extraction from solution with concentration $10 \mathrm{mg}-\mathrm{Eq} / \mathrm{L}$ and time depending on regeneration quantity are shown. It can be seen on picture 2, that after regeneration there are two sites on a diagram: a gradual loss of effectiveness in the interval from 5 to $70 \mathrm{~min}$ and a sharp drop after $70 \mathrm{~min}$. It is noted, that the maximum effectiveness made up $77 \%$ after the first regeneration, and after the second one it reached $65 \%$. By these curves time parameters of cleaning in dynamic conditions were determined: the time of 
protective action (to $50 \%$ of cleaning effect) and the time of full dynamic exchange capacity attainment.

On figure 3 there is the duration of the protective action time of filter depending on regeneration quantity (a) and dependence of time of the of full dynamic exchange capacity attainment depending on regeneration quantity (б).

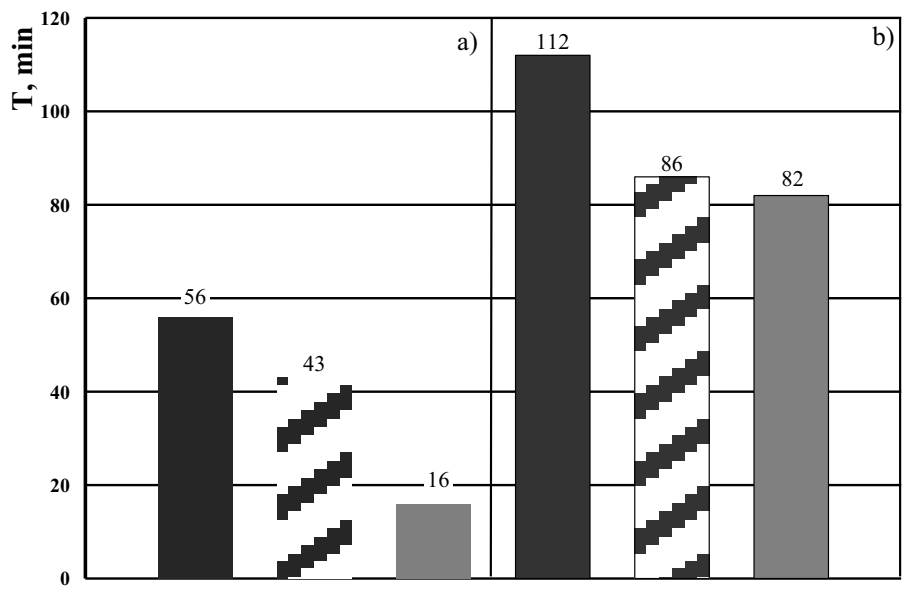

Fig. 3. The dependence of the protective action time of filter (a) and the dependence of the time of full dynamic exchange capacity attainment (б) on regeneration amount.

As it can be seen, after the first regeneration the protective action time falls by $23 \%$ (to $43 \mathrm{~min}$ ), after the second regeneration it is more - by $64 \%$ (in comparison with the 1 st regeneration).

The time of full dynamic exchange sorbent capacity attainment determination showed that regeneration reduces it (on average by $25 \%$ ), but it is not reduced depending on the quantity of regeneration.

In spite of the fact that the protective action time reduces significantly after regeneration, the time of full dynamic exchange capacity attainment changes insignificantly, that means, that material can be used before its full saturation.

\section{Conclusion}

- $\quad$ Betonite and paraffine-based material can be used for water cleaning from the hardness ions. As it has been studied, the effectiveness of cleaning by this material is comparable with of cation resin Lewatit effectiveness.

- The full dynamic exchange capacity of the research material was determined, that came up to $0,31 \mathrm{mg}-\mathrm{Eq} / \mathrm{g}$ after the first cycle of regeneration, after three regenerations it was $0,21 \mathrm{mg}-\mathrm{Eq} / \mathrm{g}$.

- The protective action time and the time of full dynamic exchange capacity attainment have been reduced from 56 to $16 \mathrm{~min}$ after the first regeneration and from 112 to $82 \mathrm{~min}$ after the second regeneration.

\section{References}

1. The state report about the state and protection of the environment in the Altai region in 2010. Barnaul, 175 p. (2011)

2. Belikov Ed. S.Water Treatment: A Handbook. Moscow: Aqua-Therm, p. 240. (2007) 
3. Sanitary rules and norms 2.1.4.1074-01 for drinking water. Hygienic requirements for water quality of centralized drinking water supply systems. Quality control. $2^{\text {nd }}$ ed. Moscow , p.127. (2002)

4. Nazarenko O., ZarubinaR., Veysgeym A.Bulletin of the Tomsk Polytechnic University. $3^{\text {rd }}$ ed. Tomsk, p.28-32. (2011)

5. Vigdorovich V., Tsygankova L., Nikolenko D.,Aculov A., Rumyantsev F. Sorption and chromatographic processes. Tomsk, p 121-126. (2010)

6. KomarovV., Ratko A.The Adsorbents: preparation, structure, properties. Minsk: Belarus Science, 256 p. (2009)

7. Kurtukova L., Somin V., KomarovaL., BotsenkoA. Polzunovsky Gazette. $4^{\text {th }}$ ed. Barnaul, p. 150-152. (2011)

8. Kurtukova L., Somin V., Komarova L.The success of modern science. $12^{\text {th }}$ ed. Barnaul, p. 29-31. (2011)

9. Kurtukova L., Somin V., Komarova L. Polzunovsky Gazette. $3^{\text {rd }}$ ed. Barnaul, p. 217219. (2012)

10. Patent. RF №2345834 RU, MPK51 B01J20 / 16, B01D39 / 06.A method of producing filter-sorption material.

11. Patent RF №2394628 RU, MPK51 B01D39 / 14, B01J20 / 22. A method of producing an ion-exchange sorption material.

12. GOST 20255.2-89. Ion exchangers. Methods for determination of dynamic exchange capacity.

13. RD 52-24.395-2007. Water hardness.Methods of measurement by titrimetric method with Trilon $B$. 